\title{
Detailed off-line parameter identification of Synchronous generator based on frequency response tests
}

\author{
Topic number: Educational
}

\begin{abstract}
This work clearly shows a general methodology, based on Standstill Frequency Response Tests indicated on IEEE Std 115-A. It allows calculating the direct and quadrature axis operational impedances of a salient pole synchronous generator from a chosen circuit topology. The novel and educational approach, is based on the fact that the order of the circuit can be whatever, even a customized circuit topology since the methodology does not rely on a set of a given formulation, but in a general and reproducible comprehensible approach. Nowadays many methods are presented in the literature to calculate such a parameters, but with the dedicated data processing and analysis methodology, time constants and reactances identification is carried out, resulting in an inexpensive accurate and harmlessness methodology.
\end{abstract}

Index Terms - Synchronous genetaror, standstill tests, equivalent circuit, identification parameters.

\section{NOMENCLATURE}

$d$-axis armature voltage $[\mathrm{V}]$

$q$-axis armature voltage $[\mathrm{V}]$

Field voltage [V]

voltage between two armature terminals during test [V]

$d$-axis armature current [A]

$q$-axis armature current $[\mathrm{A}]$

Field current [A]

Armature current during test $[\mathrm{A}]$

Armature resistance $[\Omega]$

Field resistance referred to the armature $[\Omega]$

$d$-axis damper winding resistance, $k=1,2 \ldots n[\Omega]$

$q$-axis damper winding resistance, $k=1,2 \ldots n[\Omega]$

Armature leakage inductance $[\mathrm{H}]$

$d$-axis armature to rotor mutual inductance $[\mathrm{H}]$

$q$-axis armature to rotor mutual inductance $[\mathrm{H}]$

Field winding leakage inductance $[\mathrm{H}]$

$d$-axis damper winding leakage inductance, $k=1,2 \ldots n[\mathrm{H}]$

$q$-axis damper winding leakage inductance, $k=1,2 \ldots n[\mathrm{H}]$

$d$-axis operational inductance

$q$-axis operational inductance

$d$-axis open circuit transient time constant $[\mathrm{s}]$

$d$-axis open circuit subtransient time constant [s]

$q$-axis open circuit transient time constant [s]

$q$-axis open circuit subtransient time constant [s]

$d$-axis short circuit transient time constant $[\mathrm{s}]$

$d$-axis short circuit subtransient time constant [s]

$q$-axis short circuit transient time constant [s]

$q$-axis short circuit subtransient time constant [s]

operational impedance measured between two armature

terminals during $d$-axis tests

operational impedance measured between two armature

terminals during $q$-axis tests

\section{$Z_{d}(s)$ \\ $Z_{q}(s)$ \\ $G(s)$ \\ $d$-axis operational impedance \\ $q$-axis operational impedance \\ Armature to field transfer function \\ Armature to field transfer impedance \\ I. INTRODUCTION}

$\mathrm{N}$ OWADAYS there is a trend to move toward "more electric aircraft", that is, replace hydraulic and pneumatic sources of power to relay on electrical power, such as actuators, deicing, engine -start, cabin air-conditioning, among others. As a consequence the electrical power requirement is expected to easily overpass $1 \mathrm{MW}$. Typical aircraft generators are rated at $120 \mathrm{kVA}$, so new electrical system architectures are expected [1], but the core of the system is still the synchronous generator. On the other hand, regarding the machine's medialization, the Park's model has survived until now, by means of adding resistor-inductance branches, more effects can be modelled, such a second or third order effects. In the literature second order model if synchronous machine is referred to as SSFR2 and the third order as SSFR3. By means of these models different issues can be studied, for example calculation of voltage regulation, fault identification and analysis, small and large disturbance analysis, exciters designs, high performance controllers development [2]. In this context the need of a reliable and feasible set of circuit parameters is mandatory, this has been and is still a challenging investigation line.

Parameter identification is classified into two methods, i.e. off-line and on-line identification respectively. In off-line methods the machine is out of service, among them one can find open circuit frequency response, dc-excitation methods and standstill frequency response [3], which is used into IEEE Std. 115-A, and in the methodology of this work .

However, the determination of the subtransient reactances, in both axes, under saturation conditions is crucial for the calculation of the electrical and mechanical integrity of the machine during a three phase or two phase short-circuit [4].

Besides, the estimation of the machine flux linkages is difficult, due to the strong saturation in the operation of the machine, which in turn causes the cross-saturation effect.

Thus, flux-linkages are function of both $\mathrm{d}$ and $\mathrm{q}$ axis currents although the Standstill frequency response modelling is used here because the $\mathrm{d}$ and $\mathrm{q}$ axis are decoupled and this method allows an accurate determination of high order models since the sinusoidal signal can excite almost all frequencies with the same amplitude. Besides, the sinusoidal signals are easy to noise decorrelation [5]. This parameter estimation 
methodology consists on extracting the time constants applying curve-fitting and then the equivalent circuit parameters are obtained by solving a set of non-linear equations. In the literature these non-linear equations are solved through numerical optimization and this is a process full of numerical difficulties [6-8]

It should be noted however that on-line methods are receiving much attention because of their minimal impact and interference in the operation of the machine, which is in service [9-12] such that no interference occurs in the operation of the system. Mainly they belong to time domain tests by using a small perturbation on the machine terminals, standstill time domain test, and load rejection test, but the standstill frequency response test is still used because its reliability its harmlessness to the machine with a relatively simple measurement set-up.

Furthermore, on-line identification methods can be classified into three categories, white-box, black-box and grey-box modelling. The white box modelling, knows exactly the topology of the system the parameters are to be calculated or estimated, that is exists a theoretical model because the physical knowledge is known a priori, among them extended Kalman filter [13], conjugate gradient method, neural networks, maximum likelihood, evolutionary programming, orthogonal series functions, and Hartley series can be found in the literature [14]. The black box however, is based on the input-output data because no physical knowledge is known, in such a way that is known as a data driven model. On the other hand the grey box is in between, is a hybrid model wherein the analytical equations and input-output data relations are used to obtain the parameters of the model. In this context a white model is used here because the topology of the circuit is known and the order is assumed.

But from an educational perspective, a general methodology is presented, in such a way that from a customized chosen circuit topology, it is able to obtain the circuit parameters, based on Matlab software.

The work is divided into five sections. In Section II is presented the required tests, based on the IEEE Std. 115-A, on $\mathrm{d}-\mathrm{q}$ axis for data extraction. Section III develops the general methodology for machine parameters determination. Section IV presents the obtained results and its validation. Finally, Section V presents the conclusions.

\section{StAnDStill FREQUENCY RESPONSE TeStS}

In this work a method based on IEEE Std 115A-1987 is described for obtaining synchronous machine parameters by performing frequency response tests with the machine at standstill. Usually the second order d- and q-axis equivalent circuits, Fig. 1and Fig. 2, are used to analyze the synchronous machine stability.

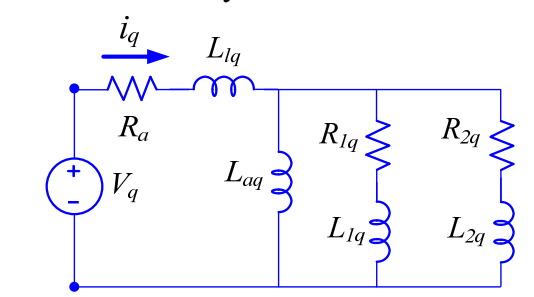

Fig.1. q-axis equivalent circuit
The procedure for calculating the synchronous machine parameters requires curve-fitting techniques which is done in an easy and intuitive way by using the Matlab software.

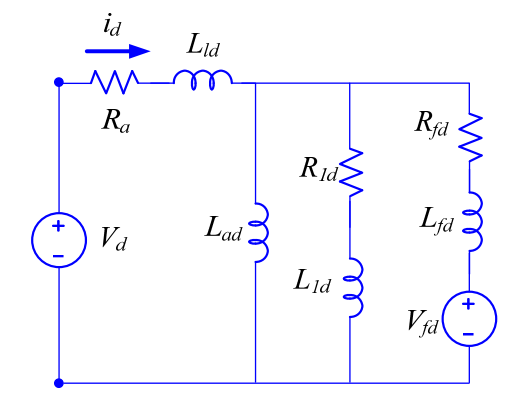

Fig.2. d- axis equivalent circuits

The $d$ - and $q$-axis operational impedances are respectively

$Z_{d}(s)=R_{a}+s \cdot L_{d}(s)$

$Z_{q}(s)=R_{a}+s \cdot L_{q}(s)$

and both can be evaluted through small changes in armature voltage and current when the field winding is short-circuited, by positioning the rotor, respectively, for $d$ - and $q$-axis tests:

$Z_{d}(s)=-\frac{\Delta e_{d}(s)}{\Delta i_{d}(s)} \mid \Delta e_{f d}=0$
$Z_{q}(s)=-\frac{\Delta e_{q}(s)}{\Delta i_{q}(s)} \mid \Delta e_{f d}=0$

Additional measures must be taking into account depending on the order $d$ - and $q$-axis equivalent circuits required to simulate accurately the transient behaviour of the synchronous machine. These measurable parameters are the armature to field transfer function, $G(s)$, and the armature to field transfer impedance, $Z_{\text {afo }}(s)$. The armature to field transfer function can be evaluted through small changes in field and armature currents when the field winding is short-circuited:

$s G(s)=\frac{\Delta i_{f d}(s)}{\Delta i_{d}(s)} \mid \Delta e_{f d}=0$

While the armature to field transfer impedance can be evaluated through small changes in field voltage and armature current when the field winding is in open-circuit:

$Z_{\text {afo }}(s)=-\frac{\Delta e_{f d}(s)}{\Delta i_{d}(s)} \mid \Delta i_{f d}=0$

In order to show how the general methodology based on Standstill Frequency Response works, the second order $d$ - and $q$-axis equivalent circuits are chosen, but this methodology can be applied to other equivalent circuits that can be found in IEEE Std 115-A. If secon order equivalent circuits are chosen then only two measurable parameters are required over a range of frequencies, these are $d$ - and $q$-axis operational impedances. The first step is to position the rotor for $d$-axis tests by doing the connections shown in Fig. 3. After that the amplifer is set to approximately $100 \mathrm{~Hz}$. The next step is to turn the rotor slowly until the observed field voltage is nulled. When this condition is accomplished the magnetic axis of the field winding is aligned with the series connection of phase $a$ and $b$. 


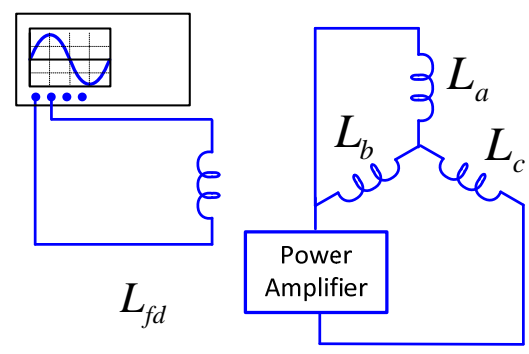

Fig. 3. Positioning the rotor for d-axis tests

After the $d$-axis is positioned the $d$-axis tests can be started by doing the connections shown in Fig. 4., where $a$ and $b$ armature phases are supplied by using a frequency variable power amplfier, and $c$ phase is in open-circuit.

The field circuit will be short circuited with a non-inductive metering shunt. Connect the voltage and current measurements of the stator winding to the measurement instrument. Perform the measurement over a bandwidth from $0,001 \mathrm{~Hz}$ to $1000 \mathrm{~Hz}$.
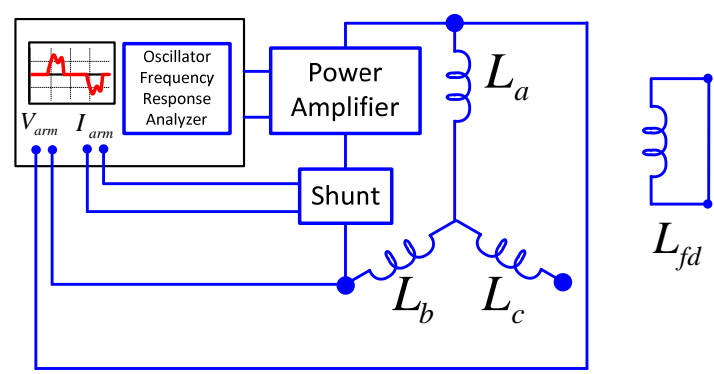

Fig. 4. d- axis impedance transfer function test

Similarly, once the $q$-axis is positioned the $q$-axis tests can be started by doing the connections shown in Fig. 5. The field circuit will be short circuited as aforementioned and the same bandwidth is applied, as presented in Fig.6.
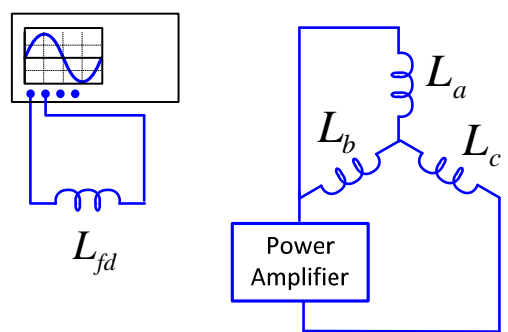

Fig. 5. Wiring of armature and field winding for rotor positioning for quadrature axis test

\section{Methodology}

The design methodology proposed in this work starts with the definition of the topology of d-q axis circuits, as aforesaid mentioned in this work a SSFR2 is used, but it must be noted that this methodology can be properly applied to whatever circuit representation.

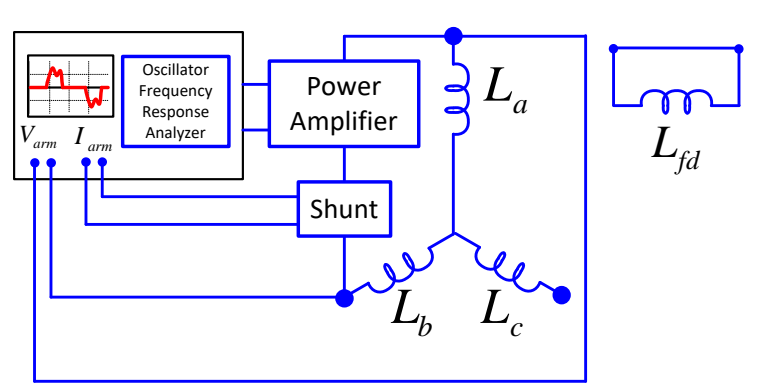

Fig. 6. Quadrature axis impedance transfer function test

The leakage inductance is needed, be it taken from the zero power factor test or taken from the manufacturer.

\section{A. d-axis parameters from tests}

From the d-axis impedance transfer function test the armature voltage and current are measured depending on the frequency, so the operational impedance measured between two armature terminals during d-axis tests, $Z_{\text {armd }}(\mathrm{s})$, can be calculated from its relation. In this test there is the series connection of the windings then d-axis operational impedance is:

$Z_{d}=\frac{Z_{\text {arm }}}{2}$

The result is shown in Fig. 7

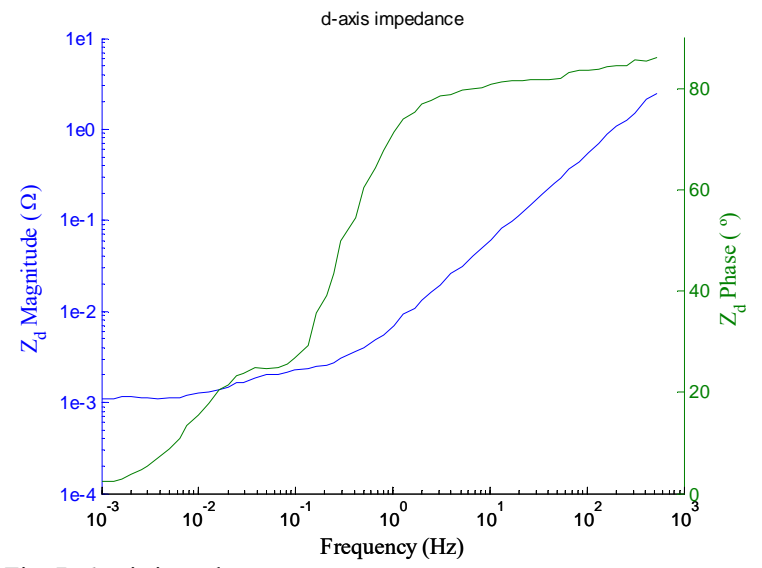

Fig. 7. $d$-axis impedance

The armature resistance, $R_{a}$, can be obtained from the real component of $Z_{d}(s)$ extrapolated at zero frequency.

The operational inductance is d-axis is

$$
L_{d}(s)=\frac{Z_{d}(s)-R_{a}}{s}
$$

The $d$-axis inductance at zero frequency $L_{d}(0)$ can be calculated extrapolating $L_{d}(s)$ to zero frequency as shown Fig. 8.

The direct-axis armature to rotor mutual inductance is obtained from the difference between the d-axis inductance at zero frequency and the leakage inductance as follows: 


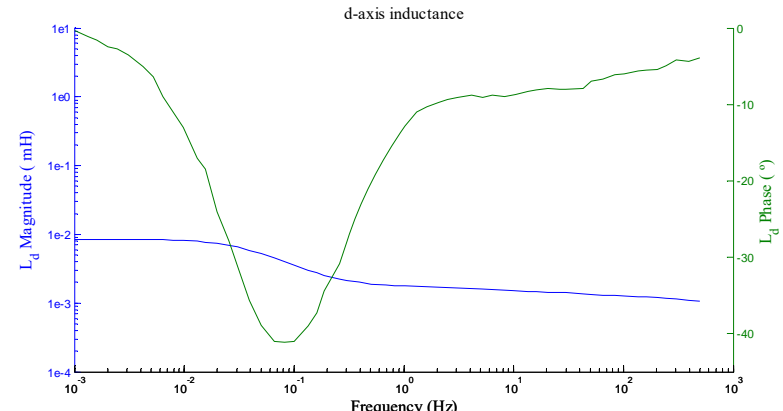

Fig. 8. $d$-axis inductance

$$
L_{a d}=L_{d}(0)-L_{l}
$$

\section{B. d-axis equations set}

The first step is to define the symbolic parameters that are represented in the equivalent circuit. The following steps consist on the association of the components in order to obtain the symbolic transfer function. The time constants presented in equation (\#), which depends on the circuit order, are fitted with the experimental data shown in Fig. 8.

$$
L_{d}(s)=\frac{L_{d}(0) \cdot\left(1+s \cdot T_{d}^{\prime}\right) \cdot\left(1+s \cdot T^{\prime \prime}{ }_{d}\right)}{\left(1+s \cdot T_{d 0}^{\prime}\right) \cdot\left(1+s \cdot T_{d 0}^{\prime \prime}\right)}
$$

$\mathrm{L}_{\mathrm{d}}(0)$ is the direct axis inductance in the low frequency bandwidth.

The fitted coefficients are equal to the corresponding constant time in the transfer function. In this way, an equation system can be obtained in order to find the parameters of the circuit. It must be solved in order to obtain the rest of the model parameters in Fig. 2, that is, $\mathrm{L}_{\mathrm{fd}}, \mathrm{L}_{1 \mathrm{~d}}, \mathrm{R}_{1 \mathrm{~d}}, \mathrm{~L}_{\mathrm{fd}}$.

\section{C. q-axis parameters}

As, in d-axis, the armature impedance measurement for each sampling frequency will be obtained from the quadrature axis impedance transfer function test, from which the quadrature-axis operational impedance is obtained, as shown in equation

$$
Z_{q}=\frac{Z_{\text {arm }}}{2}
$$

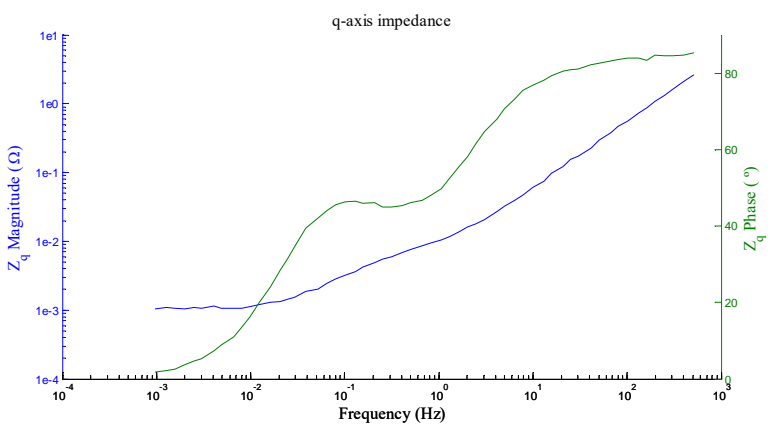

Fig. 9. $q$-axis impedance

The quadrature operational inductance is

$$
L_{q}(s)=\frac{Z_{q}(s)-R_{a}}{s}
$$

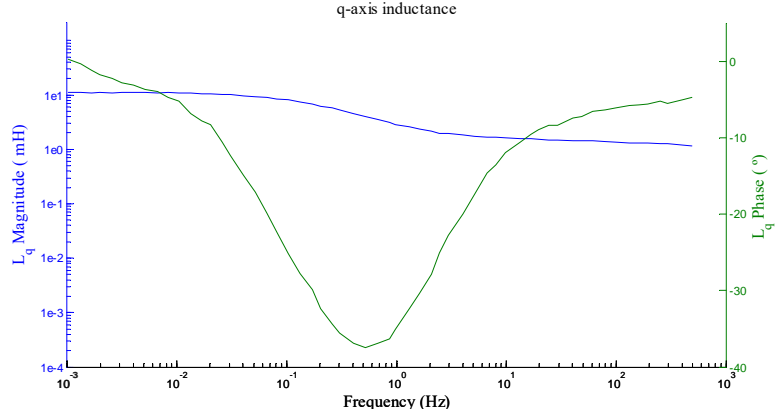

Fig. 10. $q$-axis inductance

The q-axis inductance at zero frequency $\mathrm{L}_{\mathrm{q}}(0)$ can be calculated extrapolating $\mathrm{L}_{\mathrm{q}}(\mathrm{s})$ to zero frequency. And similar to equation (9), from this value subtracting the leakage inductance the quadrature inductance is calculated

$$
L_{a q}=L_{q}(0)-L_{l}
$$

\section{D. q-axis equations set}

By means of the same procedure the rest of the model parameters for $\mathrm{q}$-axis equivalent circuit $\mathrm{L}_{1 \mathrm{q}}, \mathrm{R}_{1 \mathrm{q}}, \mathrm{L}_{2 \mathrm{q}}, \mathrm{R}_{2 \mathrm{q}}$, are determined by curve-fitting technique from the operational $\mathrm{L}_{\mathrm{q}}(\mathrm{s})$.

$L_{q}(s)=\frac{L_{q}(0) \cdot\left(1+s \cdot T_{q}^{\prime}\right) \cdot\left(1+s \cdot T^{\prime \prime}{ }_{q}\right)}{\left(1+s \cdot T_{q 0}^{\prime}\right) \cdot\left(1+s \cdot T^{\prime \prime}{ }_{q 0}\right)}$

$\mathrm{L}_{\mathrm{q}}(0)$ is the direct axis inductance in the low frequency bandwidth.

The algorithm applied on both axes, for this purpose is exposed below.

1: Set the d-q circuits SSFRi order, or another customized circuit topology.

2: Obtain module and argument of d-axis operation impedance

3: Obtain resistance of armature

4: Obtain module and argument of d-axis operation inductance

6: Determination time constants

Curve fitting: invfreqs command from Matlab care must be taken when choosing the weighting factors.

5: Obtain set of equations by means of symbolic toolbox

children and collect Matlab commands to properly equation manipulation

6: Solve set of equations, fsolve command from Matlab

7: If with the obtained parameters, the dynamic simulated behavior of the machine does not agree with experimental data then go to 1 else

8: end

Algorithm 1. Solving procedure to obtain the machine parameters

For the sake of better understanding the scheme of the procedure is shown in Fig. 11. 


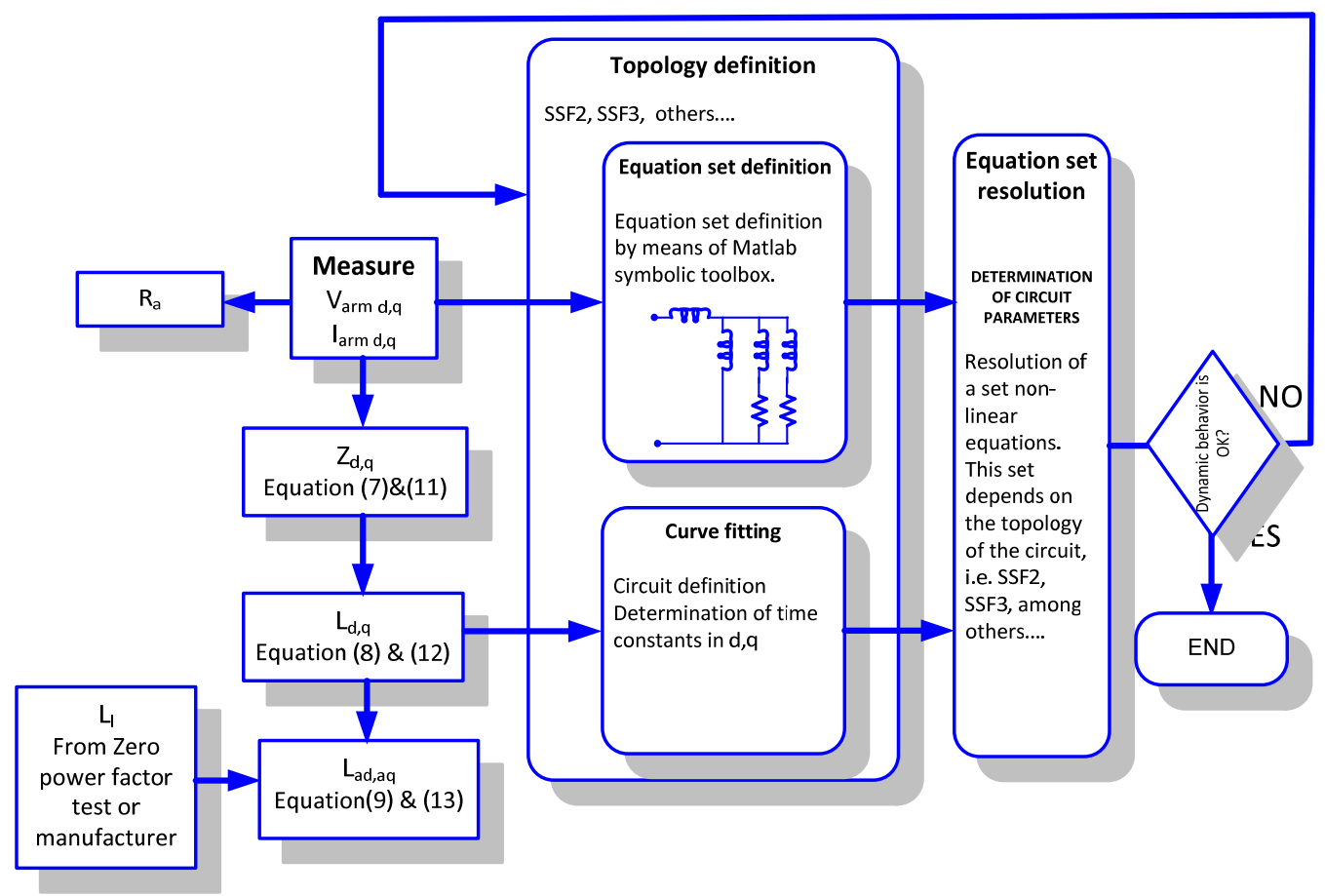

Fig. 1. Algorithm flow chart

\section{RESUltS AND VALIDATION}

The proposed methodology approach is applied to the machine used in the Std. in order to validate the obtained results, for the sake of clarity here indicated, i.e. 192.8 MVA, $18 \mathrm{kV}, 60 \mathrm{~Hz}$.

The obtained results are shown in Fig. 12 and Fig. 13, where are presented the data obtained by means of the tests indicated in Section II, with the calculated according to the presented methodology in Section III.

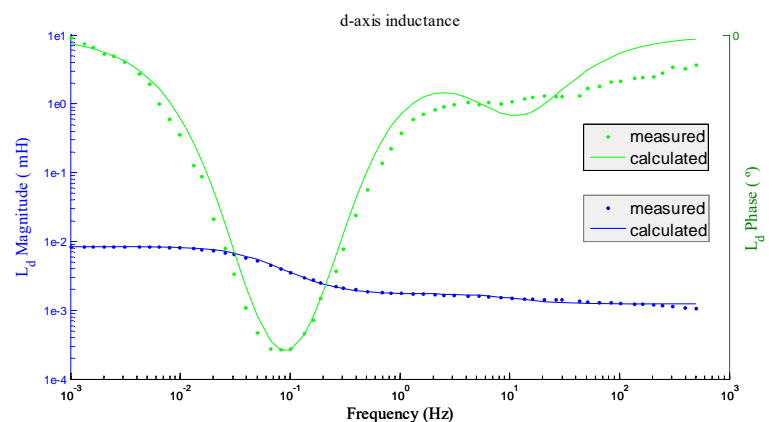

Fig. 12. Experimental and calculated d-axis operational inductance

$\begin{array}{ll}R_{a} & 0.0016[\Omega] \\ R_{f d} & 0.0021[\Omega] \\ R_{1 d} & 0.0934[\Omega] \\ R_{1 q} & 0.0126[\Omega] \\ R_{2 q} & 0.0116[\Omega] \\ L_{l} & 0.000795[\mathrm{H}] \\ L_{a d} & 0.007155[\mathrm{H}]\end{array}$

$\begin{array}{ll}L_{a q} & 0.007155[\mathrm{H}] \\ L_{f d} & 0.000985[\mathrm{H}] \\ L_{1 d} & 0.000617[\mathrm{H}] \\ L_{1 q} & 0.000522[\mathrm{H}] \\ L_{2 q} & 0.0109[\mathrm{H}] \\ T{ }_{d 0} & 3.89[\mathrm{~s}] \\ T{ }^{\prime}{ }_{d 0} & 0.0156[\mathrm{~s}] \\ T_{q 0} & 1.83[\mathrm{~s}] \\ T,{ }_{q 0} & 0.3251[\mathrm{~s}] \\ T{ }_{d}{ }_{d} & 0.8018[\mathrm{~s}] \\ T,{ }_{d} & 0.011[\mathrm{~s}] \\ T{ }^{\prime}{ }_{q} & 0.999[\mathrm{~s}] \\ T,{ }_{q} & 0.094[\mathrm{~s}]\end{array}$

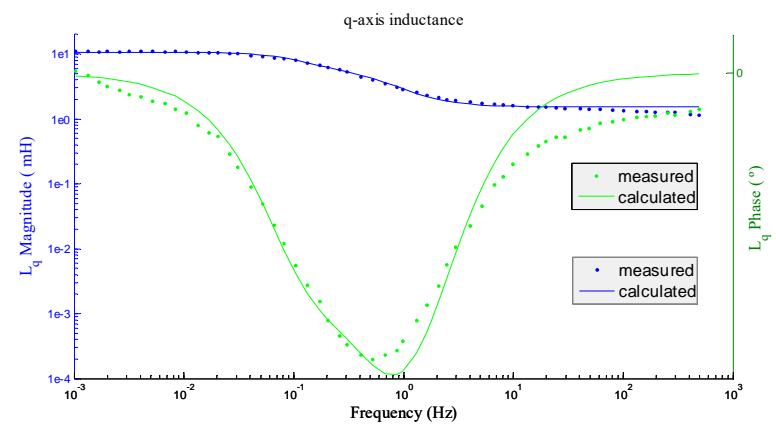

Fig. 2. Experimental and calculated q-axis operational inductance

\section{CONCLUSIONS}

This works has presented a methodology for synchronous generators d-q equivalent circuit calculation parameters based on IEEE Std 115-A.

The obtained values by the presented methodology are in good agreement with than that of reported experimentally. The 
novel and educational approach, is based on the fact that the order of the circuit can be whatever, even a customized circuit topology since the methodology does not rely on a set of a given formulation, but in a general and reproducible comprehensible approach, resulting fast and easy to implement.

\section{ACKNOWLEDGMENT}

This work has been partially supported by the Generalitat de Catalunya under the project SGR 2017 SGR 967 and the European Commission through the Clean Sky program under the project 755332-AEMS-IdFit.

\section{FUNDING}

This project has received funding from the Clean Sky 2 Joint Undertaking under the European Union's Horizon 2020 research and innovation program under grant agreement No 755332 .
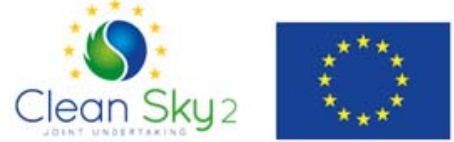

This project

was funded by the European Union

\section{DISCLAIMER}

(C) European Union, 2020

The information and views set out in this publication are those of the authors and do not necessarily reflect the official opinion of the European Union. Neither the European Union institutions and bodies nor any person acting on their behalf may be held responsible for the use which may be made of the information contained therein.

Reproduction is authorized provided the source is acknowledged.

\section{REFERENCES}

[1] A. Griffo, R. Wrobel, P. H. Mellor and J. M. Yon, "Design and Characterization of a Three-Phase Brushless Exciter for Aircraft Starter/Generator," in IEEE Transactions on Industry Applications, vol. 49, no. 5, pp. 2106-2115, Sept.-Oct. 2013
[2] R. Wamkeue, C. Jolette, A. B. M. Mabwe, and I. Kamwa, "Crossidentification of synchronous generator parameters from RTDR test timedomain analytical responses, "IEEE Trans. Energy Convers.,vol. 26, no. 3, pp. 776-786, Sep. 2011.

[3] B. Zaker, G. B. Gharehpetian, M. Karrari and N. Moaddabi, "Simultaneous Parameter Identification of Synchronous Generator and Excitation System Using Online Measurements," in IEEE Transactions on Smart Grid, vol. 7, no. 3, pp. 1230-1238, May 2016

[4] F. Maurer, M. T. Xuan and J. J. Simond, "Two Full Parameter Identification Methods for Synchronous Machine Applying DC-Decay Tests for a Rotor in Arbitrary Position," in IEEE Transactions on Industry Applications, vol. 53, no. 4, pp. 3505-3518, July-Aug. 2017.

[5] H. Radjeai, A. Barakat, S. Tnani and G. Champenois, "Identification of synchronous machine by Standstill Frequency Response (SSFR) method influence of the stator resistance -," The XIX International Conference on Electrical Machines - ICEM 2010, Rome, 2010, pp. 1-5.

[6] R. M. Saunders, "Synchronous-machine standstill frequency-response test data analysis," in IEEE Transactions on Energy Conversion, vol. 6, no. 3, pp. 564-571, Sep 1991.

[7] J. Bladh, M. Wallin, L. Saarinen and U. Lundin, "Standstill Frequency Response Test on a Synchronous Machine Extended With Damper Bar Measurements," in IEEE Transactions on Energy Conversion, vol. 31, no. 1, pp. 46-56, March 2016.

[8] E. C. Bortoni and J. A. Jardini, "A standstill frequency response method for large salient pole synchronous machines," in IEEE Transactions on Energy Conversion, vol. 19, no. 4, pp. 687-691, Dec. 2004.

[9] T. L. Vandoorn, F. M. De Belie, T. J. Vyncke, J. A. Melkebeek, and P. Lataire, "Generation of multisinusoidal test signals for the identification of synchronous-machine parameters by using a voltage-source inverter, "IEEE Trans. Ind. Electron., vol. 57, no. 1, pp. 430-439, Jan. 2010.

[10] S. Pillutla and A. Keyhani,"Neural network observers for on-line tracking of synchronous generator parameters, "IEEE Trans. Energy Conversion, vol. 14, pp. 23-31, Mar. 1999

[11] Melgoza, R. Jesus, G. T. Heydt, and A. Keyhani,“An algebraic approach for identifying operating point dependent parameters of synchronous machine using orthogonal series expansions, "IEEE Trans. Energy Conversion, vol. 16, pp. 92-98, Mar. 2001.

[12] H. B. Karayaka, A. Keyhani, G. T. Heydt, B. L. Agrawal and D. A. Selin, "Synchronous generator model identification and parameter estimation from operating data," in IEEE Transactions on Energy Conversion, vol. 18, no. 1, pp. 121-126, Mar 2003.

[13] B. Aubert, J. Régnier, S. Caux and D. Alejo, "Kalman-Filter-Based Indicator for Online Interturn Short Circuits Detection in PermanentMagnet Synchronous Generators," in IEEE Transactions on Industrial Electronics, vol. 62, no. 3, pp. 1921-1930, March 2015.

[14] M. Karrari and O. P. Malik, "Identification of physical parameters of a synchronous Generator from online measurements," in IEEE Transactions on Energy Conversion, vol. 19, no. 2, pp. 407-415, June 2004. 